\title{
Biodiversity and Antimicrobial Potential of Bacterial Endophytes from Halophyte Salicornia brachiata
}

1 Sanju Singh ${ }^{1,2}$, Vishal Ghadge ${ }^{1,2 \ddagger}$, Pankaj Kumar ${ }^{1,2 \ddagger}$, Doniya Elze Mathew ${ }^{2,3}$, Asmita

2 Dhimmar ${ }^{1,2}$, Harshal Sahastrabudhe ${ }^{1,2}$, Yedukondalu Nalli ${ }^{1}$, Mina R. Rathod ${ }^{1}$, Pramod B.

3 Shinde ${ }^{1,2 *}$

$4 \quad{ }^{1}$ Natural Products \& Green Chemistry Division, CSIR-Central Salt and Marine Chemicals Research Institute (CSIR-

5 CSMCRI), Council of Scientific and Industrial Research (CSIR), Bhavnagar-364002, Gujarat, India

$6 \quad{ }^{2}$ Academy of Scientific and Innovative Research (AcSIR), Ghaziabad-201002, India

$7 \quad{ }^{3}$ Applied Phycology and Biotechnology Division, CSIR-Central Salt and Marine Chemicals Research Institute (CSIR-

8 CSMCRI), Council of Scientific and Industrial Research (CSIR), Bhavnagar-364002, Gujarat, India.

$9 \quad$ *These authors contributed equally.

10

11 *Correspondence:

12 Email: pramodshinde@csmcri.res.in 


\section{ABSTRACT}

15 Untapped natural habitats like halophytes, marsh land, and marine environment are suitable arena for chemical ecology

16 between plants and microbes having environmental impact. Endophytes constitute an ecofriendly option for the

17 promotion of plant growth and to serve as sustainable resources of novel bioactive natural products. The present study

18 focusing on biodiversity of bacterial endophytes from Salicornia brachiata, led to isolation of around 350 bacterial

19 endophytes. Phylogenetic analysis of 63 endophytes revealed 13 genera with 29 different species, belonging to 3 major

20 groups: Firmicutes, Proteobacteria and Actinobacteria. 30\% isolates belonging to various genera demonstrated broad-

21 spectrum antibacterial and antifungal activities against a panel of human, plant, and aquatic infectious agents. An

22 endophytic isolate Bacillus amyloliquefaciens 5NPA-1, exhibited strong in-vitro antibacterial activity against human

23 pathogen $S$. aureus and phytopathogen $X$. campestris. Investigation through LC-MS/MS-based molecular networking

24 and bioactivity-guided purification led to the identification of three bioactive compounds belonging to lipopeptide

25 class on the basis of ${ }^{1} \mathrm{H}$ - and ${ }^{13} \mathrm{C}-\mathrm{NMR}$ and MS analysis. To our knowledge, this is the first report studying bacterial

26 endophytic biodiversity of Salicornia brachiata and isolation of bioactive compounds from its endophyte. Overall,

27 the present study provides insights into the diversity of endophytes associated with the plants from the extreme

28 environment as rich source of metabolites with remarkable agricultural applications and therapeutic properties.

29

Keywords: Salicornia brachiata, Endophytes, Chemical ecology, Bioactive compounds, Lipopeptides. 


\section{INTRODUCTION}

33 Ecological interactions are responsible for providing prime ecosystem services. Plant mediated interactions and

34 structure of natural communities go hand in hand as they potentially link organisms of different trophic levels and add

35 chemical complexity within communities leading to surging catalog of compounds. Endophytes, impart protection to

36 plants against various abiotic or biotic stress tolerance by production of plant hormones, bioavailability of nutrients,

37 and antagonistic action to phytopathogens in turn, sustaining on the nutrients provided by plants thereof [1].

38 Endophytic bacteria facilitates plant growth and developments through various processes including nitrogen fixation,

39 phosphate solubilization, production of hormones and siderophores, and decreasing ethylene concentration [2,3].

40 Along with host plant-growth cycle, endophytes also improvise their survival mechanisms during their continuous

41 efforts to live in the host tissues [4]. Biological control within host is mediated by endophytes that promotes plant

42 growth by protecting against the attack of phytopathogens, facilitated by the production of siderophores, antibiotics

43 or bacteriocins [5]. It has been proved that bioactive compounds derived from plants are mostly secondary metabolic

44 products of microbes inhabiting inside the plants symbiotically defined as endophytes [6]. Predominantly,

45 actinobacterial and bacterial endophytes contribute heavily in plant growth promotion and agriculture management

46 strategies via production of metabolites such as aromatic compounds, lipopeptides, plant hormones, polysaccharides,

47 and several enzymes linked to phenylpropanoid metabolism [7].

48 Halophytes are plants that thrive in saline environment with salinity upto $200 \mathrm{mM}$ concentration [8]. Endophytic

49 bacteria and fungi isolated from halophytes aid hosts by altering plant hormone status and uptake of nutrient elements

50 and/or modulating the production of reactive oxygen species through different mechanisms [9,10]. Strains of Bacillus

51 amyloliquefaciens are reported to enhance plant growth promotion and also provide defense benefits against

52 phytopathogens like Phytophthora parasitica var. nicotiana, Fusarium oxysporum sp., F. graminearum, F. solani,

53 Alternaria alternate etc. [11,12]. Beneficial metabolites produced due to ecological interactions between endophyte-

54 plant can be harnessed and employed for multifaceted applications in arena such as agriculture, medicine,

55 bioremediation, and biodegradation. Despite their beneficial characters, the research regarding endophytes from plants

56 inhabiting extreme environments is still at an early stage with respect to diversity of endophytes, their functional roles,

57 and bioprospecting for bioactive compounds.

Salicornia brachiata is a halophyte with medicinal properties having salty marsh lands as the natural habitat getting exposed to extremities of salinity, heat, temperature, and humidity [13]. S. brachiata was reported to harbor plantgrowth promoting microorganisms [14,15]. It can be hypothesized that S. brachiata being a plant inhabiting in extreme environment, must have evolved ways to harbor diverse kinds of endophytes apart from plant-growth promoters and to employ those endophytes for protection from herbivores and pests including phytopathogenic fungi and insects, competing for nutrients including trace elements. Motivated by this hypothesis, present study investigated diversity of bacterial endophytes associated with the halophyte $S$. brachiata sampled at three distinct locations at Gujarat coast, India. Further, their bioactive potential was also studied against a panel of human, plant, and aquatic infectious agents. 
67 amyloliquefaciens. This may be the first comprehensive study evaluating bacterial endophytic biodiversity of the halophyte Salicornia brachiata.

\section{METHODS}

\section{Collection of plant material and isolation of endophytes}

71 Healthy and fresh plant samples of S. brachiata were collected randomly from three different sites i.e. New port (N

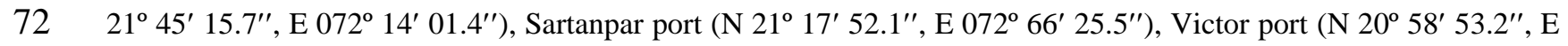

$\left.73071^{\circ} 33^{\prime} 21.2^{\prime \prime}\right)$, located along Gujarat coast, India (Figure 1). Samples were placed in sample bags and stored on

74 icebox right after sampling to preserve microbial flora and then the plant material was transported to laboratory and 75 processed immediately.

76 The plant material was surface sterilized followed by different treatments to enhance the probability of maximum 77 number of novel bacterial or actinobacterial species. Surface sterilization of the samples was carried out by reported 78 method [16]. Sterilized samples were aseptically fragmented into small pieces and directly placed on eight selective 79 media prepared with cycloheximide and nystatin at concentration of $50 \mathrm{mg} / \mathrm{ml}$ to inhibit fungal growth. Sterilized 80 samples were given six different pre-treatments (Table I) and plates were incubated at $30^{\circ} \mathrm{C}$ for 2 to 8 weeks. Control 81 plates inoculated with last wash of sterilization procedure was incubated to check effectiveness of surface sterilization 82 in triplicate. Periodic growth analysis and subsequent sub-culturing for purification of isolates was performed. 83 Glycerol stocks of purified strains were prepared and stored at $-80^{\circ} \mathrm{C}$.

\section{Identification of endophytes}

85 DNA isolation was performed using reported protocol with some modification [17]. Briefly, $2 \mathrm{ml}$ of $24 \mathrm{~h}$ grown 86 bacterial culture ( $48 \mathrm{~h}$ for slow growing bacteria) was centrifuged for $2 \mathrm{~min}$ at $13000 \mathrm{rpm}$. Cell pellet was resuspended 87 in $600 \mu \mathrm{l} \mathrm{TE}$ buffer (10 mM Tris base, $1 \mathrm{mM}$ EDTA, pH 8.0). $100 \mu \mathrm{l}$ of $10 \mathrm{mg} / \mathrm{ml}$ lysozyme was added and incubated 88 at $37^{\circ} \mathrm{C}$ for $1 \mathrm{~h}$ followed by addition of $20 \mu \mathrm{l}$ of $20 \mathrm{mg} / \mathrm{ml}$ Proteinase $\mathrm{K}$ and incubation at room temperature for further

$891 \mathrm{~h}$. After incubation, $200 \mu \mathrm{l}$ of $10 \%$ SDS was added and kept at $55{ }^{\circ} \mathrm{C}$ for $1 \mathrm{~h}$ followed by purification through 90 extraction of aqueous phase with phenol : chloroform : isoamyl alcohol (24:24:1). DNA was precipitated using 3M 91 sodium acetate and chilled isopropanol and the obtained DNA pellet was washed by ethanol. 16S rRNA amplification 92 was done using universal primer sequences of FD1 (5'-GAGTTTGATCCTGGCTCA-3') and RP 2 (5'93 ACGGCTAACTTGTTACGACT-3'). Reaction mixture, consisting of DNA template $-1 \mu \mathrm{l}(50 \mathrm{ng} / \mu \mathrm{l})$, Primers -0.5 $94 \mu \mathrm{l}$ of $10 \mu \mathrm{M}$, dNTP $-0.2 \mathrm{mM}$ and Taq polymerase -1.25 units, was prepared and the reaction was performed in 95 Thermocycler (Bio-Rad T100) with conditions: Initial denaturation $-95^{\circ} \mathrm{C}$ for $5 \mathrm{~min}, 34$ cycles of $95{ }^{\circ} \mathrm{C}$ for $30 \mathrm{~s}, 58$ $96{ }^{\circ} \mathrm{C}$ for $30 \mathrm{~s}$ and $55^{\circ} \mathrm{C}$ for $1 \mathrm{~min}$ and final amplification for $5 \mathrm{~min}$.

97 Amplification of 16S rRNA gene was confirmed by gel electrophoresis; subsequently PCR products were purified 98 with Qiagen PCR purification kit and sequenced by Macrogen Inc. Korea. The obtained sequences were trimmed to 99 align in BioEdit software (version 7.0.5.3) [18] and consensus sequence created was searched in NCBI GenBank 100 database using BLAST. Further, 16S rRNA sequences were aligned and used to construct maximum likelihood 101 phylogenetic tree using molecular evolutionary genetic analysis MEGA 6 software [19]. 


\section{Statistical data analysis}

103 Simpson index of diversity and Shannon-Wiener's diversity index were calculated to determine endophytic diversity

104 obtained from samples of all the three locations [20].

105 Simpson's index of diversity (D) gives the probability that two individuals selected at random will belong to the same

106 species and was calculated using formula as given in the following equation:

$$
D=1-\Sigma p i^{2}
$$

108 Shannon-Wiener diversity index $(\mathrm{H})$ determines actual diversity of the bacterial endophytes, and was calculated using

109 the following equation:

$$
H=-\Sigma p i(\ln p i)
$$

111 where $\mathrm{p}_{\mathrm{i}}=\mathrm{n} / \mathrm{N}$;

$112 \mathrm{n}=$ total number of organisms of species ' $\mathrm{i}$ '.

$113 \mathrm{~N}=$ total number of organisms of all species.

114 Shannon evenness (E) was calculated as $\mathrm{H}^{\prime} / \mathrm{H}_{\max }$, where $\mathrm{H}_{\max }=\ln (\mathrm{S}$ ), with $\mathrm{S}$ as the total number of species in the 115 sample. Further, to determine qualitative wealth species richness was also calculated by $\mathrm{S} / \sqrt{ } \mathrm{N}$.

\section{Antimicrobial potential of endophytes}

117 A panel of 8 reference human, plant, and marine pathogens comprising of Staphylococcus aureus MCC 2043, Bacillus 118 subtilis MCC 2049, Mycobacterium smegmatis MTCC 6, Escherichia coli MCC 2412, Candida albicans MCC 1152, 119 Xanthomonas campestris NCIM 5028, Fusarium oxysporum NCIM 1008, Alteromonas macleodii NCIM 2815 was 120 employed to determine bioactive potential of all the endophytic isolates. $10 \mathrm{ml}$ culture of endophytes in $50 \mathrm{ml}$ tubes 121 was done for a period of 14 days at $30^{\circ} \mathrm{C}, 180 \mathrm{rpm}$ shaking condition, in-between assessing it at an interval of 7 days 122 for the antimicrobial activity. Whole cell culture and supernatant (obtained after centrifugation) were used to perform 123 well diffusion assay [21] for determination of bioactivity.

\section{Preparation of crude extracts}

125 In order to confirm endophytes play important role in survival of halophyte S. brachiata in extreme climate by 126 protecting against pathogens, crude extracts of isolates which were found bioactive in primary screening were 127 prepared. Briefly, $250 \mathrm{ml}$ culture broth in $1000 \mathrm{ml}$ Erlenmeyer flask in particular medium and incubation conditions 128 specific for an isolated strain was done. After incubation period, culture broths were extracted twice with equal volume 129 of ethyl acetate. Organic phase was collected over anhydrous sodium sulfate and concentrated under rotary evaporator 130 to yield dark-brown colored crude extracts. The activity of crude extracts of isolates bioactive against S. aureus MCC 1312043 and $X$. campestris NCIM was confirmed through disk diffusion assay by loading $1 \mathrm{mg}$ of extract on the disk 132 following Clinical and Laboratory Standards Institute (CLSI) protocols [22].

\section{LC-MS/MS based molecular networking}

134 LC-MS/MS data of the crude extract of B. amyloliquefaciens 5NPA-1 was studied with GNPS (Global natural products 135 social molecular networking) (https://gnps.ucsd.edu) [23]. Raw data received from Agilent 6545 Q-TOF LC/MS was 136 converted into GNPS compatible mzXML format using MSconvert application (version 3.0.19317-0ef6e44d0) in 
137 Proteowizard suit [24]. The converted file was uploaded to GNPS server (massive.ucsd.edu) using WinSCP FTP 138 client. Molecular networking was run as classical molecular networking work flow (METABOLOMICS-SNETS-V2) 139 with activated MS-Cluster. Parameters for input algorithm were set as: precursor ion mass tolerance 2.0 Da, fragment 140 ion mass tolerance $0.5 \mathrm{Da}$, minimum cosine score for an edge formation by two consensus MS/MS spectra as 0.7, 141 minimum number of common fragment ions as 6 (no. of fragment shared by two separate consensus MS/MS spectra

142 in order to be connected by an edge in the molecular network), minimum cluster size was 2, and edges between two 143 nodes were considered only if both nodes were within top 10 most similar nodes of each other. Molecular network 144 file was downloaded in GraphML format and visualized using Cytoscape (version 3.7.2) [25].

\section{TLC bioautography}

146 Ethyl acetate extract of endophyte B. amyloliquefaciens 5NPA-1 was subjected to thin layer chromatography (TLC) 147 analysis over analytical aluminium silica gel 60 TLC plate for separation of metabolites to obtain $\mathrm{R}_{\mathrm{f}}$ value of active 148 fraction. The crude extract was dissolved in methanol to get a concentration of $10 \mathrm{mg} \mathrm{ml}^{-1}$ and $1 \mathrm{mg}$ was loaded on 149 TLC plate which was developed with solvent system comprising of methanol and chloroform in the ratio 12:88. 150 Separate bands were observed under short wavelength UV light and their $\mathrm{R}_{\mathrm{f}}$ values were calculated. To perform 151 bioautography, $1.5 \mathrm{ml}$ of $1 \%$ mueller hinton agar (MHA) was spread on the developed TLC plate of size $10 \times 2 \mathrm{~cm}$ 152 under sterile environment of biosafety cabinet and $50 \mu \mathrm{l}$ of $\log$ phase culture of $S$. aureus MCC 2043 was spread with 153 the help of sterile spreader. After incubation for $24 \mathrm{~h}$ at $30{ }^{\circ} \mathrm{C}$, the plate was visualized by spraying 154 iodonitrotetrazolium chloride solution (INT, $2 \mathrm{mg} \mathrm{ml}^{-1}$ ) pink color on plates signified cell growth whereas bands with 155 clear zone indicated inhibition of cell growth. $\mathrm{R}_{\mathrm{f}}$ values of the bands with clear zone were recorded [26].

\section{Isolation and identification of bioactive molecules}

157 Purification of compounds was carried out by separating $50 \mathrm{mg}$ of crude extract on preparative TLC plates (Kieselgel

$15860 \mathrm{~F}_{254}, 25 \mathrm{~mm}$, Merck) using the same solvent system as above. Based on TLC bioautography, the active portion was 159 selectively scrapped and dissolved in methanol. The supernatant was concentrated on rotary evaporator to obtain 15 $160 \mathrm{mg}$ of yellow, viscous oil (5-PTLC2), which was analyzed by HPLC. Further, ${ }^{1} \mathrm{H}-\mathrm{NMR}$ spectrum (Bruker, Avance II $161500 \mathrm{MHz}$ in $\mathrm{CD}_{3} \mathrm{OD}$ ) of 5-PTLC2 was acquired in order to identify the class of compounds. Additionally, to purify 162 active compounds, the crude extract (2 g) was fractionated by MPLC (C18 RP-silica gel) eluting with aqueous MeOH 163 (30\% to 100\%) resulting in the collection of 18 fractions (fr. 1-fr. 18) which were evaluated for antimicrobial activity 164 against S. aureus MCC 2043. Fractions 11 and 13 containing bioactive compounds were further chromatographed on 165 semi-preparative HPLC (Dionex Ultimate 3000, Thermo Scientific) using gradient mixtures of acetonitrile-water (4:1 166 to 9:1) on YMC column (YMC-Triart C18, $5 \mu \mathrm{m}, 250 \times 10 \mathrm{~mm}$ I.D.) to yield three compounds (1-3). The three 167 compounds were further characterized by MALDI-MS and MALDI-MS/MS (Applied Biosystems 4800 MALDI 168 TOF-TOF analyzer) and NMR (JEOL $600 \mathrm{MHz})$.

\section{$170 \quad$ RESULTS}

\section{Collection of plant material and isolation of endophytes}


172 S. brachiata samples collected from three different sites along Gujarat coast (Fig. 1) were processed using eight

173 different media with six variable pretreatments resulting in isolation of 336 endophytes differentiated on the basis of

174 morphological characters (Fig. S1). The high number of isolates obtained were also found to be equally diversified.

175 Also, effectiveness of surface sterilization was established as no growth was observed on the negative control plate

176 even when incubated for a month long period. Maximum number of bacterial isolates were obtained on medium

177 supporting fast growing microbes i.e. 81 isolates collectively from NA, ZMA, and TSA; 52 from SCA; 52 from ISP2;

17850 from AIA; 70 from ISP4; 31 from TWYA (Fig. S2). The diverse group of isolated actinobacteria preferred ISP4

179 media for their growth and pigment production.

\section{Identification of endophytes}

181 Out of 336 isolates, 63 isolates obtained from different media were identified on the basis of molecular phylogeny by

182 16S rRNA sequencing. Evolutionary relationships of different endophytes obtained from S. brachiata were inferred

183 from maximum likelihood phylogenetic tree (Fig. 2). On the basis of 16S rRNA sequencing results, the most

184 predominant as well as diverse genera identified was Bacillus being $76 \%$ of the isolates with 15 different species. The

185 remaining percentage accounted for various genera of actinomycetes or bacteria like Isoptericola, Paenibacillus,

186 Nocardiopsis, Rhodococcus, Salinicola, Jonesia, Nitratireductor, Enterococcus, Streptomyces, Micromonospora,

$187 \quad$ Pseudomonas and Marinilactibacillus (Table II).

\section{Statistical data analysis}

$189 \alpha$-diversity indexes, i.e. Shannon- Wiener diversity index and Simpson's index of diversity and their components;

190 richness and evenness were used to determine diversity of the endophytic community isolated from S. brachiata

191 sampled from three different locations. Shannon-Wiener diversity index (H) was calculated as 3.028, indicating high

192 diversity within endophytes. Species richness indicating abundance of the species in a sample was found to be

193 3.615,viz., greater the value higher the richness. Shannon evenness measures relative abundance of different species

194 contributing to richness of a sample, was calculated as 0.899 signifying an even community structure [20]. In

195 agreement with aforementioned data, Simpson's index of diversity (D) of 0.931, demonstrate a high diversity of

196 endophytes harbored by the host halophyte (Table III).

197 Antimicrobial potential of endophytes

198 From the primary screening study, a total of 101 isolates were found to exhibit broad-spectrum antimicrobial activity

199 against one or the other pathogen from panel of pathogens tested. 8 isolates were found to be active against $M$.

200 smegmatis MTCC 6; 20 against $S$. aureus MCC 2043; 51 against X. campestris NCIM 5028; 42 against A. macleodii

201 NCIM 2815; 12 against $C$. albicans MCC 1152; 14 against $F$. oxysporum NCIM 1008; 19 against $B$. subtilis MCC

$2022049 ; 5$ against $E$. coli MCC 2412 (Fig 3a). It was observed that some endophytes displayed inhibition activity against

203 two or more pathogens (Table IV).

204 Preparation of crude extracts and 
Crude extract of bioactive strains were prepared through solvent-solvent extraction method. Bioactivity of isolates active against S. aureus MCC 2043 and X. campestris NCIM 5028 was confirmed by disk diffusion assay (Fig. 3b), according to the guidelines of CLSI. The isolate Bacillus amyloliquefaciens 5NPA-1 exhibited a prominent zone of inhibition of $29 \mathrm{~mm}$ and $14 \mathrm{~mm}$ against pathogens S. aureus MCC 2043 and X. campestris NCIM 5028 respectively, serving as a potential isolate for isolation of bioactive compounds which are beneficial to plants as well as humans.

$210 \quad$ LC-MS/MS based molecular networking

211 Molecular networking of crude extract of B. amyloliquefaciens 5NPA-1 using the GNPS platform was found to consist 212 of 24 nodes grouped into 4 clusters. Largest cluster had 5 nodes, which was annotated as surfactin by automatic 213 dereplication using MS/MS spectral libraries available at GNPS (Fig. 4). The network resulted into identification of 2143 types of surfactin with respect to variations in length of fatty acid chain. Further, no specific networks denoting other 215 class compounds were observed, supporting the idea that lipopeptides in B. amyloliquefaciens 5NPA-1 could be 216 responsible for the bioactivity.

\section{TLC Bioautography}

218 In order to identify bioactive metabolites, TLC plate was developed to obtain 7-8 bands as observed under short UV 219 radiations (254 nm wavelength). Developed TLC plate when overlaid with S. aureus MCC 2043 suspension on 1\% 220 agar, displayed clear zone with no cell growth against pinkish background at $\mathrm{R}_{\mathrm{f}}$ between 0.12 to 0.41 (Fig. 5).

\section{Isolation and identification of bioactive molecules}

222 The active middle band (5-PTLC-2) obtained from TLC-bioautography was scrapped in order to acquire ${ }^{1} \mathrm{H}-\mathrm{NMR}$ spectrum to identify the chemical class of the compounds. ${ }^{1} \mathrm{H}-\mathrm{NMR}$ spectrum of PTLC-2 exhibited signals for a long aliphatic alkyl chain at $\delta_{\mathrm{H}} 1.29, \mathrm{CH}_{3}$ groups at $\delta_{\mathrm{H}} 0.85-1.00$, an oxy-methine at $\delta_{\mathrm{H}} 5.31$, seven $\alpha-\mathrm{H}$ at $\delta_{\mathrm{H}} 4.05-4.80$, indicating lipopeptide nature of compounds present in the fraction PTLC2 (Fig. 6). HPLC-DAD chromatogram of PTLC-2 revealed three peaks suggesting it to be a mixture of three compounds (Fig. S3). Hence, for their targeted separation, the crude ethyl acetate (EtOAc) extract was subjected to MPLC followed by HPLC (Fig. S4) resulting three compounds 1, 2, and $\mathbf{3}$ (Fig. 7a). The MALDI-TOF-MS spectra of 1, 2, and $\mathbf{3}$ exhibited intense sodium adduct $[\mathrm{M}+\mathrm{Na}]^{+}$ion peaks at $\mathrm{m} / \mathrm{z} 1031.2147,1045.0100$ and 1058.8456, respectively. Comparison of the MALDI-TOF-MS data of $\mathbf{1}, \mathbf{2}$, and $\mathbf{3}$ with those available in literature revealed that the purified compounds belonged to surfactin class with different number of $\mathrm{CH}_{2}$ units in fatty acid chain and subsequently identified as $\mathrm{C}_{13}$-surfactin (1), $\mathrm{C}_{14}$-surfactin (2), and $\mathrm{C}_{15}$-surfactin (3) [27] (Fig. S5,S6,S7). To determine the sequence of the amino acids, the sodiated ions of $\mathbf{1}$, $\mathrm{C}$ - and N-terminus. The MS/MS spectra of compounds 1, 2, and $\mathbf{3}$ displayed a major ion sequence of fragments $\mathrm{m} / \mathrm{z}$ 707.4, 594.3, 481.2, 382.1, 267.1 corresponding to loss of (fatty acid)-Glu-Leu-Leu-Val-Asp-Leu-Leu from Cterminal region. Similarly, another major fragment ion series of 1 [m/z 945.5, 832.5, 717.4, 618.4], 2 [m/z 931.5, 818.5, 702.4, 604.3], and $\mathbf{3}$ [ $\mathrm{m} / \mathrm{z}, 917.5,804.4,688.4,590.3]$ confirmed the presence of amino acid residues sequence as Leu-Leu-Asp-Val-Leu-Leu-Glu-(fatty acid) from the N-terminal region. Taken together, the connection of the two series suggested that the surfactins $\mathbf{1}, \mathbf{2}$, and $\mathbf{3}$ contained the same heptapeptide sequence (fatty acid)-Glu-Leu-Leu- 
Val-Asp-Leu-Leu (Fig. S8,S9,S10). ${ }^{13} \mathrm{C}$ NMR chemical shifts allowed to differentiate branching of the hydroxy fatty acid side chain among the normal $\left(\delta_{\mathrm{C}} 13.8,22.0,31.2\right)$, iso $\left(\delta_{\mathrm{C}} 22.4,22.4,27.3,38.4\right)$, and the anteiso $\left(\delta_{\mathrm{C}} 11.1\right.$, and 19.0) chain types [28]. Based on this approach, the $\beta$-hydroxyl fatty acid chains were found to be mixtures of $i s o-\mathrm{C}_{10} \mathrm{H}_{21}$ and anteiso- $\mathrm{C}_{10} \mathrm{H}_{21}$ in $\mathbf{1} ; n-\mathrm{C}_{11} \mathrm{H}_{23}$, iso- $\mathrm{C}_{11} \mathrm{H}_{23}$, and anteiso- $\mathrm{C}_{11} \mathrm{H}_{23}$ in 2 ; and, iso- $\mathrm{C}_{12} \mathrm{H}_{25}$ and anteiso- $\mathrm{C}_{12} \mathrm{H}_{25}$ in $\mathbf{3}$, respectively (Fig. 7b). On the basis of the previous studies, absolute configurations of amino acid units from $\mathrm{N}$ - to $\mathrm{C}$-terminal of $\mathbf{1}$,

2, and 3 were assumed to be L-, L-, D-, L-, L-, D- and L-, respectively, and the C-3 configuration of fatty acid was assumed to be as $R[29]$.

\section{DISCUSSION}

248 Endophytes, plant associated symbionts, have emerged as an interesting source for natural products because of their 249 diversity in bioactive secondary metabolites. Halophytes are reported to overcome their abiotic and biotic stress with 250 the help of metabolites, regulators or enzymes released from endophytes [30]. In this study, diversity of bacterial endophytes from S. brachiata was assessed and their probable role in host-plant interaction including identification of metabolites produced by one of the endophyte B. amyloliquefaciens. All endophytes were screened for antimicrobial potential against human, plant, and marine pathogens. To our knowledge this is a first comprehensive report regarding diversity of bacterial endophytes from Salicornia brachiata from Gujarat coast of India and investigation of their antimicrobial potential.

256 Surface sterilized plant material with six different pretreatments and eight different previously reported media resulted into a total of 336 endophytes delivering a quantitative idea about the bacterial diversity within the halophyte. The results indicated a mixed composition of the endophyte communities comprising majorly firmicutes followed by actinobacteria and proteobacteria. Studies on endophytic bacteria from different parts of halophytes Salicornia europaea, Arthrocnemum macrostachyum etc. have been performed previously and predominance of aforementioned phyla was observed [31,32]. Out of 336 endophytes, 63 isolates identified in the study represented 13 genera with 29 different species. Bacillus as a dominant genus was observed with a diversity of around 15 different species. Bacillus sp. due to their better resilience is usually the dominant firmicute isolated from saline environments [30,33]. The statistical analysis showed a higher richness and evenness of species diversity among isolated endophytes. Amidst the endophytes obtained in our study from S. brachiata, genera Bacillus, Isoptericola, Streptomyces, Salinicola, Rhodococcus have already been reported from sister species of Salicornia europaea [32,34]. Nocardiopsis, Jonesia, Nitratireductor, Paenibacillus, Micromonospora are some genera from S. brachiata we report in our study. It is well established that endophytes support plant ecological progression through production of various metabolites. Processes supported by these metabolites increases bioavailability of nutrients to host, tolerance against abiotic stress and strength to fight against biotic stress including pests and phytopathogens. Among the isolated strains in the study Bacillus sp. is predominantly reported to produce ACC deaminase enzymes to alleviate stress by ethylene, indole acetic acid and gibberellic acids promoting cell division and growth [30], phosphate solubilization enzymes, biological nitrogen fixation, siderophores and bioactive metabolites against phytopathogens [5,31,35]. Bioactive metabolites

274 from Bacillus sp. include polyketides bacillomycin, fengycin, iturin, lichenysin, mycosubtilin, plipastatin, 275 pumilacidin, and surfactin [36]. Hence, abundance of Bacillus endophytes can be validated due to its profuse chemical 
important for plant growth promotion events in stress conditions [34]. Moreover, endophytic Salinicola sp. isolated from Spartina maritima was reported to be an excellent producer of siderophores and contain heavy metal tolerant genes thereby supporting the plant to alleviate the toxic effect of heavy metals [37]. The actinobacterial genera of Nocardiopsis and Isoptericola [38] thrive in the saline conditions. Genetic makeup of Nocardiopsis is filled with megaplasmid genes encoding antibiotic productions like apoptolidin, lipopeptide biosurfactants, thiopeptides, griseusin D etc., heavy metal resistance and stress response including osmoregulation benefitting their survival in halophilic environment [39]. It can be said that the ecological stress within host plant stimulated production of such bioactive metabolites in Nocardiopsis. Jonesia denitrificans as the name suggests is reported to perform denitrification [40]. Various strains of Streptomyces are reported to exhibit phosphate solubilization property, ammonia production, enzymes production for breakdown of organic matter, PKS and NRPS gene clusters for production of bioactive compounds etc. which contributes to plant health either directly or indirectly [41]. These reports reflect direct plantmicrobe interactions of the isolates obtained in study, further supporting their endophytic origin from halophyte.

In-vitro screening of the isolates for bioactivity revealed one third of the population to be bioactive against one or more reference pathogen. This aligns with the work of Verma et al. who reported $60 \%$ of the endophytic actinobacteria isolates obtained from Azadirachta indica showed wide-spectrum antagonistic potential [42]. Given their metabolite productions, a large number of isolates exhibited inhibition of growth of plant pathogens X. campestris NCIM 5028, F. oxysporum NCIM 1008 and marine bacterial pathogen A. macleodii NCIM 2815. Inhibition of phytopathogens at such enormous amount indicates role of endophytes in defense mechanisms of host plant. Some of the isolates were found to inhibit M. smegmatis MTCC 6, S. aureus MCC 2043, etc., suggesting that the antimicrobial activity exhibited by plant $S$. brachiata [13] can be attributed to the bioactive metabolites secreted by inhabiting endophytes. The genus Bacillus was dominant in displaying activity against all indicator pathogens pertaining to its siderophore and bioactive lipopeptide production potential. Production of siderophores was reported from halotolerant Bacillus isolated from wheat seedlings, further it improve soil fertility increasing plant productivity in agriculture and also remediates toxic metals from human body [43]. Bacillus sp. have been isolated as endophytes from ginger, turmeric etc. and shows enormous antifungal properties and antibacterial properties due to the presence of cyclic lipopeptides [44].

In the present work, along with endophytic biodiversity, an emphasis was also laid on isolate displaying activity against S. aureus MCC 2043, a common nosocomial pathogen and X. campestris NCIM 5028, a meticulous plant pathogen. Crude extract of isolate B. amyloliquefaciens 5NPA-1 (MT459305) was found to be most potent with zone of inhibition of $29 \mathrm{~mm}$ and $14 \mathrm{~mm}$ against S. aureus MCC 2043 and X. campestris NCIM 5028 respectively. Molecular networking using LC-MS/MS data of crude extract gave an idea about the presence of secondary metabolites encrypted in the strain B. amyloliquefaciens 5NPA-1 indicating surfactin type compounds. High potency of crude extract served as a driving force for purification of bioactive compounds to identify its potential as strong antimicrobial agents. Following that paradigm, purification and characterization of active compounds from B. amyloliquefaciens 5NPA-1 was also performed leading to compounds 1-3 belonging to lipopeptides class. Lipopeptides form an 311 important class of metabolites from endophytic bacteria, wherein serving as antibiotic and inducing plant systemic 312 resistance. B. amyloliquefaciens was recognized as a higher lipopeptide producer when isolated from different plants

313 including Phaseolus vulgaris, Oryza sativa, Ophiopogon japonicus, Musa acuminata, marine plants etc., meanwhile 
314 also secreting plant growth promoters, phyto-hormones, siderophores, antifungal, anticancer and antimicrobial agents

315 [36]. Diversity of endophytes within plant structures is proportional to various benefits of plant-microbe interactions.

316 Such interactions are of ecological importance as they improve adaptation capabilities of either species and improve

317 soil fertility and texture. An understanding of the chemical ecology of plants-microorganisms should enable the

318 development of new crop improvement strategies, the conservation of indigenous varieties, and definitely a source of

319 interesting pharmaceutical compounds.

320 To conclude, present study was the first attempt where endophytic bacterial community residing in stress-tolerant

321 halophyte $S$. brachiata was studied and examined for the production of antimicrobial compounds against pathogens

322 of various niches. Through identification of $20 \%$ isolates, it was revealed that the plant harbors a rich bacterial

323 biodiversity accounting for 13 genera and 29 species with Bacillus being dominant and distinct actinobacteria

324 exhibiting different morphology, producing pigments, metabolites and polysaccharides which benefits the plant.

325 Metabolites from species inhabiting the plant have history in supporting the host plant through various chemical

326 interactions. It was also deciphered that surfactin class molecules produced by endophytic strain B. amyloliquefaciens

327 5NPA-1 possess high biocontrol properties against nosocomial pathogen and bacterial plant pathogen. Bacillus

328 amyloliquefaciens being an environmentally stable and fast replicating bacteria serves as an ideal source for extraction

329 of plethora of metabolites. Such enormous antimicrobial potencies displayed by several endophytes from S. brachiata

330 indicate their role in plant defense system, and serve as an example of plant microbe interaction. This diverse

331 population can be further explored for novel metabolites given that demand for novel bioactive agents is everlasting

332 and it may help us with better understanding the chemical ecology of an ecosystem.

\section{Data Availability Statement}

334 The datasets generated for this study are available on request to corresponding author.

335 Conflict of Interest

336 The authors declare that the research was conducted in the absence of any commercial or financial relationships that 337 could be construed as a potential conflict of interest.

\section{Author Contributions}

339 Sanju Singh, Vishal Ghadge, Pankaj Kumar, and Pramod B. Shinde designed and planned the research. Sanju Singh,

340 Vishal Ghadge, and Pankaj Kumar isolated and identified the bacterial strains. Sanju Singh and Doniya Elze Mathew 341 performed bioactivity. Pankaj Kumar performed molecular networking analysis. Sanju Singh, Asmita Dhimmar,

342 Pankaj Kumar, Harshal Sahastrabudhe, and Yedukondalu Nalli isolated and identified bioactive secondary 343 metabolites. All authors analyzed and interpreted the results and commented on the manuscript prepared by Sanju

344 Singh and Pramod B. Shinde.

\section{$345 \quad$ Funding}

346 This research was supported by Scientific and Engineering Research Board (SERB), Department of Science and

347 Technology [ECRA/2016/000788 and EEQ/2016/000268]; and Council of Scientific and Industrial Research 348 [MLP/0027].

\section{Acknowledgments}


Sanju Singh, Doniya Elze Mathew, Asmita Dhimmar acknowledges CSIR-JRF fellowship from Council of Scientific and Industrial Research (CSIR), Pankaj Kumar acknowledges DBT-JRF fellowship from Department of

352 Biotechnology (DBT) and Harshal Sahastrabudhe acknowledges GATE-JRF fellowship from Council of Scientific

353 and Industrial Research (CSIR). Yedukondalu Nalli acknowledges Scientific and Engineering Research Board

354 (SERB) for providing National Postdoctoral Fellowship (N-PDF).

355 Supplementary Material

356 A schematic diagrams of isolation of endophytes and compounds, HPLC chromatograms, fragmentation pattern, and

357 MS- and MS/MS-spectra of compounds $\mathbf{1}-\mathbf{3}$ is available.

358 REFERENCES

359 1. Palazzotto E and Weber T (2018) Omics and multi-omics approaches to study the biosynthesis of secondary metabolites in microorganisms. Curr Opin Microbiol 45:109-116. doi:10.1016/j.mib.2018.03.004

2. Glick BR (2012) Plant growth-promoting bacteria: mechanisms and applications. Scientifica. doi:10.6064/2012/963401

3. Ryan RP, Germaine K, Franks A, Ryan DJ, Dowling DN (2008) Bacterial endophytes: recent developments and applications. FEMS Microbiol Lett 278:1-9 doi: 10.1111/j.1574-6968.2007.00918.x

4. Keller NP, Turner G, Bennett JW (2005) Fungal secondary metabolism from biochemistry to genomics. Nat Rev Microbiol 3:937-947 doi: 10.1038/nrmicro1286

5. Gaiero JR, McCall CA, Thompson KA, Day NJ ,Best AS, Dunfield KE (2013) Inside the root microbiome: bacterial root endophytes and plant growth promotion. Am J Bot 100:1738-1750. doi: 10.3732/ajb.1200572

6. Medema MH and Fischbach MA (2015) Computational approaches to natural product discovery. Nat Chem Biol 11:639-648. Doi:10.1038/nchembio.1884

7. Santos ML, Berlitz DL, Wiest SLF, Schunemann R, Knaak N, Fiuza LM (2018). Benefits Associated with the Interaction of Endophytic Bacteria and Plants. Braz Arch Biol Techn 61. doi:10.1590/1678-4324-2018160431

8. Flowers TJ, Colmer TD (2008). Salinity tolerance in halophytes. New Phytology 179:945-963. doi: 10.1111/j.1469-8137.2008.02531.x

9. Rodriguez-Llorente ID, Pajuelo E, Navarro-Torre S, Mesa-Marin J, Caviedes MA (2019) Bacterial Endophytes from Halophytes: How Do They Help Plants to Alleviate Salt Stress? Saline Soil-Based Agriculture by Halotolerant Microorganisms, 147-160. doi:10.1007/978-981-13-8335-9_6

10. You YH, Yoon H, Kang SM, Shin JH, Choo YS, Lee IJ, et al (2012). Fungal diversity and plant growth promotion of endophytic fungi from six halophytes in Suncheon Bay. J Microbiol Biotechnol, 22:1549-1556. doi: $10.4014 / j m b .1205 .05010$

11. Jiao R, Munir S, He P, Yang H, Wu Y, Wang J, et al (2019). Biocontrol potential of the endophytic Bacillus amyloliquefaciens YN201732 against tobacco powdery mildew and its growth promotion. Biol Control, 104160. doi:10.1016/j.biocontrol.2019.104160

12. Shahzad R, Khan AL, Bilal S, Asaf S, Lee IJ (2017). Plant growth-promoting endophytic bacteria versus pathogenic infections: an example of Bacillus amyloliquefaciens RWL-1 and Fusarium oxysporum $f$. sp. lycopersici in tomato. PeerJ, 5, e3107. doi: 10.7717/peerj.3107 
13. Patel S (2016) Salicornia: evaluating the halophytic extremophile as a food and a pharmaceutical candidate. 3 Biotech 6:1-10. doi:10.1007/s13205-016-0418-6

14. Abbas H, Patel RM, Parekh VB (2018) Culturable endophytic bacteria from halotolerant Salicornia brachiata L. Isolation and plant growth promoting traits. Ind J Applied Microbiol 21:10-21.

15. Karnwal A (2019) Screening, isolation and characterization of culturable stress-tolerant bacterial endophytes associated with Salicornia brachiata and their effect on wheat (Triticum aestivum L.) and maize (Zea mays) growth. J Plant Prot Res 59:293-303. doi:10.24425/jppr.2019.129747

16. Qin S, Li J, Chen HH, Zhao GZ, Zhu WY, Jiang CL, et al (2009) Isolation, diversity, and antimicrobial activity of rare actinobacteria from medicinal plants of tropical rain forests in Xishuangbanna, China. Appl Environ Microbiol 75:6176-6186. doi: 10.1128/aem.01034-09

17. Kieser T, Bibb MJ, Buttner, MJ, Chater KF, Hopwood DA (2000) Practical Streptomyces Genetics (Vol. 291). Norwich: John Innes Foundation.

18. Hall TA (1999) BioEdit: a user-friendly biological sequence alignment editor and analysis program for Windows 95/98/NT. Nucl Acids Symp Ser 41:95-98.

19. Tamura K, Stecher G, Peterson D, Filipski A, Kumar S (2013) MEGA6: molecular evolutionary genetics analysis version 6.0. Mol Biol Evol 30:2725-2729. doi: 10.1093/molbev/mst197

20. Qadri M, Rajput R, Abdin MZ, Vishwakarma RA, Hassan SR (2014) Diversity, molecular phylogeny, and bioactive potential of fungal endophytes associated with Himalayan blue pine (Pinus wallichiana). Microb Ecol 67:877-887. doi: 10.1007/s00248-014-0379-4

21. Balouiri M, Sadiki M, Ibnsouda SK (2016) Methods for in vitro evaluating antimicrobial activity: a review. J Pharm Anal 6:71-79. doi: 10.1016/j.jpha.2015.11.005

22. Patel JB, Tenover FC, Turnidge JD, Jorgensen JH (2011) Susceptibility test methods: dilution and disk diffusion methods. In Manual of Clinical Microbiology, 10th Edition (pp. 1122-1143). American Society of Microbiology.

23. Wang M, Carver JJ, Phelan VV, Sanchez LM, Garg N, Peng Y, et al (2016) Sharing and community curation of mass spectrometry data with Global Natural Products Social Molecular Networking. Nat Biotechnol 34:828-837. doi:101038/nbt.3597

24. Chambers MC, Maclean B, Burke R, Amodei D, Ruderman DL, Neumann S, et al (2012) A cross-platform toolkit for mass spectrometry and proteomics. Nat Biotechnol 30:918-920. doi:10.1038/nbt.2377

25. Shannon P, Markiel A, Ozier O, Baliga NS, Wang JT, Ramage D, et al (2003) Cytoscape: a software environment for integrated models of biomolecular interaction networks. Genome Res 13:2498-2504. doi:10.1101/gr.1239303

26. Valle DL, Puzon JJM, Cabrera EC, Rivera WL (2016) Thin layer chromatography bioautography and gas chromatography-mass spectrometry of antimicrobial leaf extracts from Philippine Piper betel L. against multidrug-resistant bacteria. Evid Based Complement Alternat Med 2016:1-7. doi: 10.1155/2016/4976791

27. Lee JH, Nam SH, Seo WT, Yun HD, Hong SY, Kim MK, et al (2012) The production of surfactin during the fermentation of cheonggukjang by potential probiotic Bacillus subtilis CSY191 and the resultant growth suppression of MCF-7 human breast cancer cells. Food Chem 131:1347-1354. doi: 10.1016/j.foodchem.2011.09.133 
28. Tang J S, Gao H, Hong K, Yu Y, Jiang MM, Lin HP, et al (2007) Complete assignments of ${ }^{1} \mathrm{H}$ and ${ }^{13} \mathrm{C}$ NMR spectral data of nine surfactin isomers. Magn Reson Chem 45:792-796. doi:10.1002/mrc.2048

29. Pang X, Zhao J, Fang X, Liu H, Zhang Y, Cen S et al (2017) Surfactin derivatives from Micromonospora sp. CPCC 202787 and their anti-HIV activities. J Antibiot 70:105-108. doi:10.1038/ja.2016.63

30. Sgroy V, Cassan F, Masciarelli O, Del Papa MF, Luna V (2009) Isolation and characterization of endophytic plant-growth promoting (PGPB) or stress homeostasis-regulating bacteria (PSHB) associated to the halophyte Prosopis strombulifera. Appl Microbiol Biotechnol 85:371-381. doi: 10.1007/s00253-009-2116-3

31. Navarro-Torre S, Barcia-Piedras JM, Mateos-Naranjo E, Redondo-Gomez S, Camacho M et al (2016). Assessing the role of endophytic bacteria in the halophyte Arthrocnemum macrostachyumsalt tolerance. Plant Biol 19:249256.doi:10.1111/plb.12521

32. Zhao S, Zhou N, Zhao ZY, Zhang K, Wu GH, Tian CY (2016) Isolation of endophytic plant growth-promoting bacteria associated with the halophyte Salicornia europaea and evaluation of their promoting activity under salt stress. Curr Microbiol 73:574-581.doi:10.1007/s00284-016-1096-7

33. Yaish MW, Antony I, Glick BR 2015. Isolation and characterization of endophytic plant growth-promoting bacteria from date palm tree (Phoenix dactylifera L.) and their potential role in salinity tolerance. Anton Leeuw Int J G 107:1519-1532.

34. Szymanska S, Plociniczak T, Piotrowska-Seget Z, Hrynkiewicz K (2016) Endophytic and rhizosphere bacteria associated with the roots of the halophyte Salicornia europaea L. community structure and metabolic potential. Microbiol res 192:37-51. doi: 10.1016/j.micres.2016.05.012

35. Beneduzi A, Ambrosini A, Passaglia LMP (2012) Plant growth-promoting rhizobacteria (PGPR): Their potential as antagonists and biocontrol agents. Genet Mol Biol 35:1044-1051. doi: 10.1590/s1415-47572012000600020

36. Ek-Ramos MJ, Gomez-Flores R, Orozco-Flores AA, Rodriguez-Padilla C, Gonzalez-Ochoa G, TamezGuerra P (2019) Bioactive products from plant-endophytic gram-positive bacteria. Front Microbiol 10:112.doi:10.3389/fmicb.2019.00463

37. Mesa J, Mateos-Naranjo E, Caviedes MA, Redondo-Gomez S, Pajuelo E, Rodriguez-Llorente ID (2015) Endophytic cultivable bacteria of the metal bioaccumulator Spartina maritima improve plant growth but not metal uptake in polluted marshes soils. Front microbiol 6:1450. https://doi.org/10.3389/fmicb.2015.01450

38. Tseng M, Liao HC, Chiang WP, Yuan GF (2011) Isoptericola chiayiensis sp. nov., isolated from mangrove soil. Int J Syst Evol Microbiol 61:1667-1670. doi: 10.1099/ijs.0.022491-0.

39. Cornell CR, Marasini D, Fakhr MK (2018) Molecular characterization of plasmids harbored by actinomycetes isolated from the great salt plains of oklahoma using PFGE and next generation whole genome sequencing. Front Microbiol 9:2282. doi: 10.3389/fmicb.2018.02282.

40. Pukall R, Gehrich-Schroter G, Lapidus A, Nolan M, Glavina Del Rio T et al (2009) Complete genome sequence of Jonesia denitrificans type strain (Prevot 55134). Stand Genomic Sci 1:262-269. doi:10.4056/sigs.41646 
42. Verma VC et al (2209) Endophytic actinobacteria from Azadirachta indicaa.juss.:Isolation, diversity, and antimicrobial activity. Microb. Ecol. 57, 749-756. doi: 10.1007/s00248-008-9450-3.

463 43. Ramadoss D, Lakkineni VK, Bose P, Pranita B, Sajad A, Kannepalli A (2013) Mitigation of salt stress in wheat seedlings by halotolerant bacteria isolated from saline habitats. SpringerPlus 2:6 http://dx.doi.org/10.1186/21931801- 2-6.

44. Jasim B, Sreelakshmi KS, Mathew J, Radhakrishnan EK (2016). Surfactin, iturin, and fengycin biosynthesis by endophytic Bacillus sp. from Bacopa monnieri. Microb ecol 72:106-119. doi: 10.1007/s00248-016-0753-5. 
470 Table I Location, Pre-treatments and Media used in the study.

471

\begin{tabular}{|c|c|c|}
\hline Sites of sampling & Pre-treatments & Media \\
\hline 1. New port & 1. Sample grinded by mortar pestle, & 1. Nutrient Agar (NA) \\
\hline 2. Sartanpar port & diluted and spread. & 2. Zobell Marine agar (ZMA) \\
\hline \multirow[t]{8}{*}{ Victor port } & 2. Moist incubation of grinded sample & 3. Tryptic Soya agar (TSA) \\
\hline & with $\mathrm{CaCO}_{3}$ for $7-14$ days and then & 4. Starch Casein Agar (SCA) \\
\hline & spread. & 5. Yeast Malt Agar (ISP 2) \\
\hline & 3. Rehydration and centrifugation & 6. Actinomycetes isolation agar (AIA) \\
\hline & method. & Inorganic Salts Starch agar 4 \\
\hline & Dry heating the plant at $80-100^{\circ} \mathrm{C}$. & (ISP 4) \\
\hline & 5. Treatment with $1.5 \%(\mathrm{w} / \mathrm{v})$ phenol. & 8. Tap water Yeast Extract Agar (TWYA) \\
\hline & $\begin{array}{l}\text { 6. Treatment with } 0.01 \% \text { potassium } \\
\text { dichromate. }\end{array}$ & \\
\hline
\end{tabular}


474 Table II Identification and similarity values of $16 \mathrm{~S}$ rDNA sequences retrieved from the endophytic bacteria from $S$. brachiata

475

\begin{tabular}{|c|c|c|c|c|c|}
\hline S.no. & Isolates & Identification & Accession number & Closest bacteria in database & Similarities $(\%)$ \\
\hline 1 & NPROOT-3 & Bacillus subtilis & MT459325 & B. subtilis NR_027552 & 99.86 \\
\hline 2 & NPB-5 & B. subtilis & MT645716 & B. subtilis NR_027552 & 99.93 \\
\hline 3 & NPA-10 & B. tequilensis & MT645715 & B. tequilensis NR_104919 & 99.86 \\
\hline 4 & NPA-4 & B. subtilis & MT645714 & B. subtilis NR_027552 & 99.93 \\
\hline 5 & 1VPT1-5 & Pseudomonas parafulva & MT645710 & Pseudomonas parafulva NR_104280 & 99.86 \\
\hline 6 & 1VPT5-7 & B. infantis & MT645711 & B. infantis NR_043267 & 99.63 \\
\hline 7 & 1VPT5-10 & B. infantis & MT645712 & B. infantis NR_043267 & 99.63 \\
\hline 9 & 4NPA-2 & B. safensis & MT645719 & B. safensis NR_041794 & 99.79 \\
\hline 10 & 4NPA-4 & Paenibacillus taichungensis & MT645718 & Paenibacillus taichungensis MH553940 & 99.29 \\
\hline 11 & 4SPS-3 & Nocardiopsis aegyptia & MT645720 & Nocardiopsis aegyptia NR025889 & 99.71 \\
\hline 12 & 4SPT4-10 & B. safensis & MT645721 & B. safensis NR_041794 & 99.78 \\
\hline 13 & 4SPT4-14 & B. safensis & MT645722 & B. safensis NR_041794 & 99.93 \\
\hline 14 & 4SPT4-16 & B. safensis & MT645723 & B. safensis NR_041794 & 99.79 \\
\hline 15 & 4SPT6-1 & B. safensis & MT645724 & B. safensis NR_041794 & $100 \%$ \\
\hline 16 & 4SPT6-1A & B. zhangzouensis & MT645725 & B. safensis NR_041794 & 99.79 \\
\hline 18 & 4SPT8-6A & B. subtilis & MT645727 & B. subtilis NR_113265 & 99.93 \\
\hline 19 & 4SPT12-17 & B. aerius & MT645728 & B. aerius NR_118439 & 99.86 \\
\hline 20 & 4VPT1-4 & Isoptericola chiayiensis & MT645729 & Isoptericola chiayiensis NR_116696 & 99.05 \\
\hline 21 & 4VPT1-8 & Isoptericola chiayiensis & MT645730 & Isoptericola chiayiensis NR_116696 & 99.20 \\
\hline 22 & 4VPT1-9 & B. subtilis & MT645731 & B. subtilis NR_027552 & 99.35 \\
\hline 23 & 4VPT4-5 & B. tequilensis & MT645732 & B. tequilensis NR_104919 & 99.86 \\
\hline 24 & 4VPT5-1 & B. pumilus & MT645733 & B. pumilus NR_043242 & 99.71 \\
\hline 25 & 4VPT5-1A & B. zhangzhouensis & МT645717 & B. zhangzhouensis NR_148786 & 99.35 \\
\hline 26 & 5NPA-1 & B. amyloliquefaciens & MT459305 & B. amyloliquefaciens NR_041455 & 98.91 \\
\hline 27 & 5SPRoot-1 & B. paralicheniformis & MT645735 & B. paralicheniformis MK517555 & 99.93 \\
\hline 28 & $5 \mathrm{NPB}-5$ & B. aerius & MT645734 & B. aerius NR_118439 & 99.78 \\
\hline 29 & 5SPS-3 & Rhodococcus ruber & MT645737 & Rhodococcus ruber NR_118602 & 99.93 \\
\hline 30 & 5SPT4-2 & B. tequilensis & MT645738 & B. tequilensis NR_104919 & 99.71 \\
\hline 31 & 5SPT7-2 & B. paralicheniformis & MT645740 & B. paralicheniformis MF_321822 & 99.93 \\
\hline 32 & 5SPROOT 3 & B. stratosphericus & MT645736 & B. stratosphericus NR_118441 & 99.93 \\
\hline 33 & 5SPT4-2A & B. paralicheniformis & MT645739 & B. paralicheniformis MK517555 & 99.86 \\
\hline
\end{tabular}




\begin{tabular}{|c|c|c|c|c|c|}
\hline 36 & 5VPT7-8 & B. paralicheniformis & MT645746 & B. paralicheniformis MF321822 & 99.93 \\
\hline 37 & 5VPT11-1 & Bacillus endophyticus & МT645748 & Bacillus endophyticus KY194734 & $98.8 \%$ \\
\hline 38 & 5VPT1-11 & B. tequilensis & МT645744 & B. tequilensis NR_104919 & 99.86 \\
\hline 39 & 5VPT4-11 & B. subtilis & MT645745 & B. subtilis NR_113265 & 99.86 \\
\hline 40 & 5VPT7-10 & B. subtilis & MT645747 & B. subtilis NR_112629 & 99.93 \\
\hline 41 & 5VPT1-13 & B. subtilis & MT645743 & B. subtilis NR_113265 & 99.72 \\
\hline 42 & 6SPT2-1 & $\begin{array}{l}\text { Marinilactibacillus } \\
\text { piezotolerans }\end{array}$ & MT645751 & $\begin{array}{c}\text { Marinilactibacillus piezotolerans } \\
\text { NR_112661 }\end{array}$ & 99.56 \\
\hline 43 & $6 \mathrm{NPB}-8$ & Salinicola tamaricis & MT645750 & Salinicola tamaricis NR_157001 & 99.34 \\
\hline 44 & 6SPT4-14 & B. subtilis & MT645755 & B. subtilis NR_113265 & 99.79 \\
\hline 45 & 6SPT7-1 & B. safensis & MT645752 & B. safensis NR_041794 & 99.65 \\
\hline 46 & 6SPT12-11 & Nitratireductor indicus & MT645754 & Nitratireductor indicus NR_117518 & 99.55 \\
\hline 47 & 6VPT1-2 & B. safensis & MT645756 & B. safensis NR_041794 & 99.79 \\
\hline 48 & 6VPT5-9 & B. zhangzouensis & MT645758 & B. zhangzouensis NR_148786 & 99.50 \\
\hline 49 & 6NPA-7 & B. aerius & MT645749 & B. aerius NR_118439 & 99.64 \\
\hline 50 & 6SPT8-3 & Nitratireductor indicus & MT645753 & Nitratireductor indicus NR_117518 & 99.70 \\
\hline 51 & 6VPT1-8 & B. pumilus & MT645757 & B. safensis NR_112637 & 99.57 \\
\hline 52 & 7NPA-13 & B. stratosphericus & MT645759 & B. stratosphericus NR_118441 & 99.93 \\
\hline 53 & 7NPB-1 & B. stratosphericus & MT645760 & B. stratosphericus NR_042336 & 99.86 \\
\hline 54 & 7NPB-2 & Salinicola tamaricis & MT645761 & Salinicola tamaricis NR_157001 & 98.80 \\
\hline 55 & 7VPT5-5R & Streptomyces hyderabadensis & МT645769 & Streptomyces hyderabadensis NR_116934 & 99.55 \\
\hline 56 & 7NPSHOOT-4 & B. subtilis & MT645765 & B. subtilis NR_112629 & 100 \\
\hline 57 & 7NPB-3B & B. velezensis & MT645763 & B. velezensis NR_116240 & 99.78 \\
\hline 58 & 7SPROOT-1 & Enterococcus faecalis & MT645764 & E. faecalis NR_115765 & 99.80 \\
\hline 59 & 7SPT4-20 & Enterococcus faecalis & MT645767 & E. faecalis $\mathrm{NR} \_115765$ & 99.93 \\
\hline 60 & 7SPT4-19 & Jonesia denitrificans & MT645766 & Jonesia denitrificans NR_119162 & 99.78 \\
\hline 61 & 7NPROOT-4 & B. cereus & MT645762 & B. cereus NR_115526 & 99.51 \\
\hline 62 & 7SPT5-13 & Micromonospora echinospora & MT645768 & Micromonospora echinospora NR_118843 & 99.41 \\
\hline 63 & 4NPBL & B. subtilis & MT447880 & B. subtilis NR_112116 & 99.86 \\
\hline
\end{tabular}


bioRxiv preprint doi: https://doi.org/10.1101/2020.07.15.203612; this version posted July 15, 2020. The copyright holder for this preprint (which

was not certified by peer review) is the author/funder, who has granted bioRxiv a license to display the preprint in perpetuity. It is made available under aCC-BY-NC-ND 4.0 International license.

479

Table III Diversity indices of the 63 endophytes isolated from S. brachiata

\begin{tabular}{ccc}
\hline Diversity indices & Values calculated & Range \\
\hline Shannon-Wiener diversity index & 3.028 & 0 onwards \\
Simpson's index of diversity & 0.931 & $0-1$ \\
Species richness & 3.615 & 0 onwards \\
Shannon evenness & 0.899 & $0-1$ \\
\hline
\end{tabular}

480 
Table IV Results of primary screening of endophytic isolates against microbial pathogens.

482

\begin{tabular}{|c|c|c|c|c|c|c|c|c|c|c|}
\hline $\mathrm{S} \mathrm{N}$ & Isolates & Taxonomic identification & $M S$ & $S A$ & $B S$ & $E C$ & $C A$ & $X C$ & $F O$ & $A M$ \\
\hline 1 & NPA-4 & Bacillus subtilis & & & & & & & & \\
\hline 2 & NPA-10 & Bacillus tequilensis & & & & & & & & \\
\hline 3 & NPB-5 & Bacillus subtilis & & & & & & & & \\
\hline 4 & 2VPT4-2 & & & & & & & & & \\
\hline 5 & NP ROOT-3 & Bacillus tequilensis & & & & & & & & \\
\hline 6 & 2VPT11-1 & & & & & & & & & \\
\hline 7 & 4VPT1-8 & Isoptericola chiayiensis & & & & & & & & \\
\hline 8 & 4VPT1-9 & Bacillus subtilis & & & & & & & & \\
\hline 9 & 4VPT1-4 & Isoptericola chiayiensis & & & & & & & & \\
\hline 10 & 4SPT4-14 & Bacillus safensis & & & & & & & & \\
\hline 11 & 4SPT4-10 & Bacillus safensis & & & & & & & & \\
\hline 12 & 4NPA-2 & Bacillus safensis & & & & & & & & \\
\hline 13 & 4NPA-4 & Paenibacillus taichungensis & & & & & & & & \\
\hline 14 & 4NPB-1 & & & & & & & & & \\
\hline 15 & $4 \mathrm{NPB}-4 \mathrm{~A}$ & & & & & & & & & \\
\hline 16 & 4SPT4-16 & Bacillus safensis & & & & & & & & \\
\hline 17 & 4SPT4-12 & & & & & & & & & \\
\hline 18 & 4SPT6-1A & Bacillus zhangzouensis & & & & & & & & \\
\hline 19 & 4VPT4-5 & Bacillus tequilensis & & & & & & & & \\
\hline 20 & 4VPT5-1 & Bacillus pumilus & & & & & & & & \\
\hline 21 & 4SPT8-6A & Bacillus subtilis & & & & & & & & \\
\hline 22 & 4SPT8-2 & Bacillus filamentosus & & & & & & & & \\
\hline 23 & 4SPS-1 & & & & & & & & & \\
\hline 24 & 4SPS-3 & Nocardiopsis tangguensis & & & & & & & & \\
\hline 25 & 4SPR-4 & & & & & & & & & \\
\hline 26 & 5VPT1-11 & Bacillus subtilis & & & & & & & & \\
\hline 27 & 5NPA-1 & Bacillus amyloliquefaciens & & & & & & & & \\
\hline 28 & 5NPB-5 & Bacillus aerius & & & & & & & & \\
\hline 29 & 5SPT4-9 & & & & & & & & & \\
\hline 30 & 5SPT4-8 & & & & & & & & & \\
\hline 31 & 5SPT4-1 & & & & & & & & & \\
\hline 32 & 5SPT4-2 & Bacillus tequilensis & & & & & & & & \\
\hline 33 & 5SPT6-1 & & & & & & & & & \\
\hline 34 & 5VPT1-13 & Bacillus subtilis & & & & & & & & \\
\hline 35 & 5VPT1-3 & & & & & & & & & \\
\hline 36 & 5SPT7-2 & Bacillus paralichenfiormis & & & & & & & & \\
\hline 37 & 5SPT7-4 & & & & & & & & & \\
\hline 38 & 5SPT7-7 & Bacillus tequilensis & & & & & & & & \\
\hline 39 & 5SPT8-5A & Bacillus tequilensis & & & & & & & & \\
\hline 40 & 5SPT10-5 & & & & & & & & & \\
\hline 41 & 5SP-Root-1 & Bacillus paralichenfiormis & & & & & & & & \\
\hline 42 & 5SP-ROOT-3 & Bacillus stratosphericus & & & & & & & & \\
\hline 43 & 5VPT4-11 & Bacillus subtilis & & & & & & & & \\
\hline 44 & 5VPT7-2 & Bacillus paralichenfiormis & & & & & & & & \\
\hline 45 & 5SP-SHOOT-3 & Rhodococcus ruber & & & & & & & & \\
\hline 46 & 5VPT7-8 & Bacillus haynesii & & & & & & & & \\
\hline 47 & 5VPT11-1 & Bacillus paralichenfiormis & & & & & & & & \\
\hline 48 & 6SPT2-1 & Marinilactibacillus peizotolerans & & & & & & & & \\
\hline 49 & 6NPA-7 & Bacillus aerius & & & & & & & & \\
\hline 50 & 6SPT4-2 & & & & & & & & & \\
\hline 51 & 6SPT4-14 & Bacillus subtilis & & & & & & & & \\
\hline 52 & 6SPT6-3 & & & & & & & & & \\
\hline
\end{tabular}




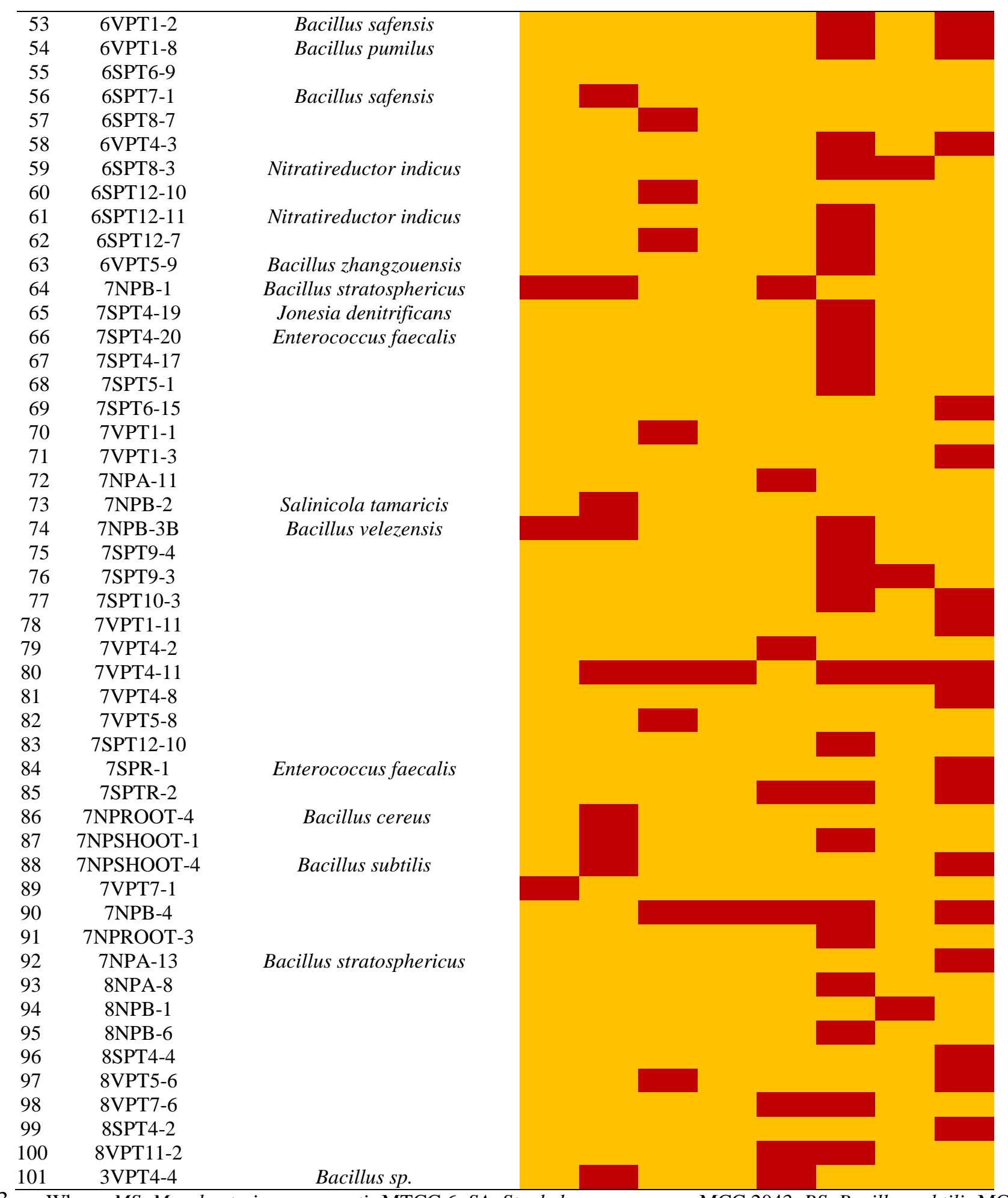

483 Where, MS: Mycobacterium smegmatis MTCC 6, SA: Staphylococcus aureus MCC 2043, BS: Bacillus subtilis MCC 484 2049, EC: Escherichia coli MCC 2412, CA: Candida albicans MCC 1152, XC: Xanthomonas campestris NCIM 5028, 485 FO: Fusarium oxysporum NCIM 1008, AM: Alteromonas macleodii NCIM 2815.

486 Red boxes: Inhibitory activity, Yellow boxes: No inhibitory activity 
bioRxiv preprint doi: https://doi.org/10.1101/2020.07.15.203612; this version posted July 15,2020 . The copyright holder for this preprint (which was not certified by peer review) is the author/funder, who has granted bioRxiv a license to display the preprint in perpetuity. It is made available under aCC-BY-NC-ND 4.0 International license.

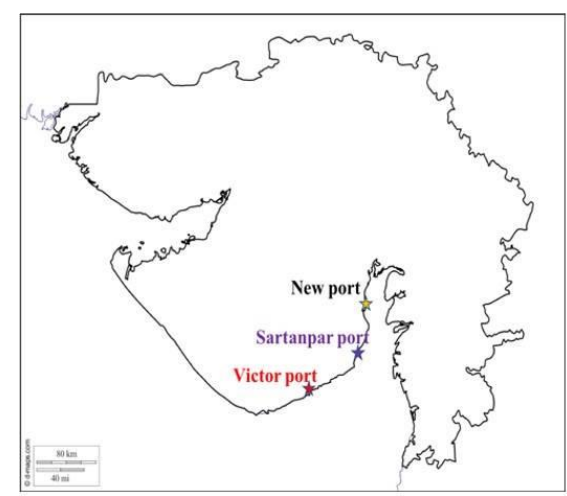

(a)

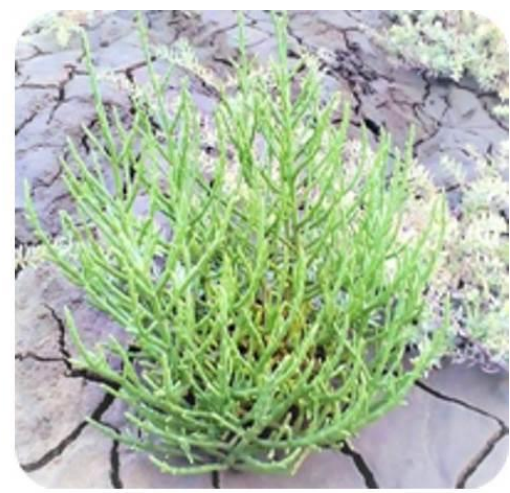

(b)

Fig. 1 Sampling location. (a) Location Map of Gujarat coast, India showing three sampling sites 1) New port, 2) Sartanpar port, 3) Victor port. (b) Morphology of Salicornia brachiata plant in natural marsh habitat 
bioRxiv preprint doi: https://doi.org/10.1101/2020.07.15.203612; this version posted July 15, 2020. The copyright holder for this preprint (which was not certified by peer review) is the author/funder, who has granted bioRxiv a license to display the preprint in perpetuity. It is made available under aCC-BY-NC-ND 4.0 International license.

Fig. 2 Identification of endophytes by $16 \mathrm{~S}$ rRNA sequencing. Phylogenetic tree of 63 bioactive isolates obtained by Maximum likelihood analysis constructed using Mega 6 software depicting their phylogeny with related genera as

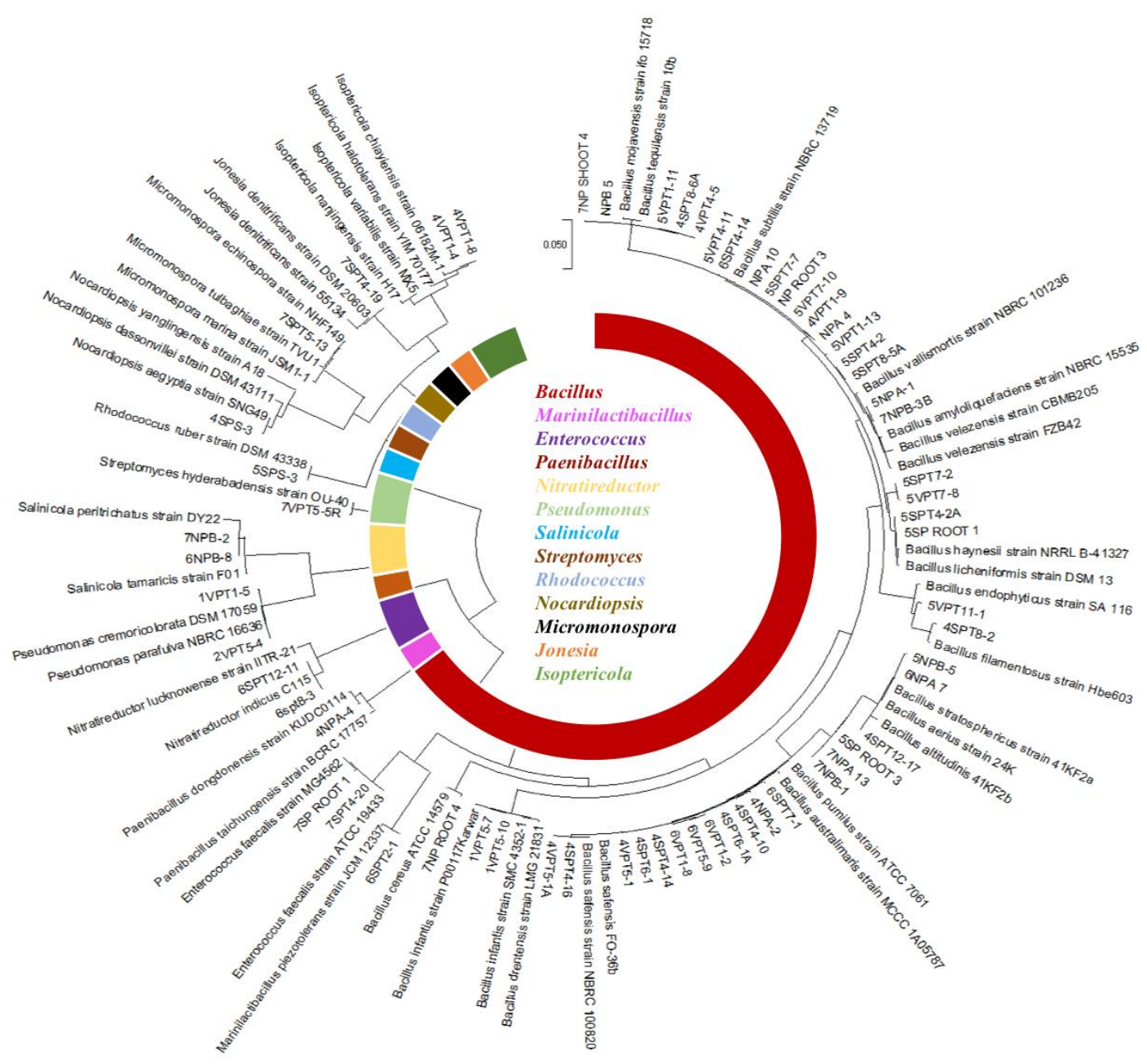
well as pie graph displaying percentage distribution of genera obtained 


\section{Percentage distribution of bioactive isolates among reference pathogens}

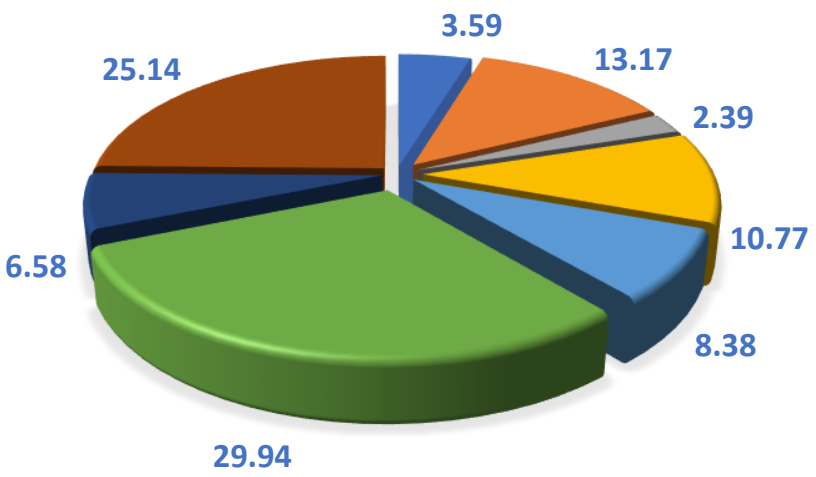

Mycobacterium smegmatis 国E.coli

G Fusarium oxysporum a Candida albicans

Staphylococcus aureus - Bacillus subtilis

Xanthomonas campestris QAltermonas macleodii

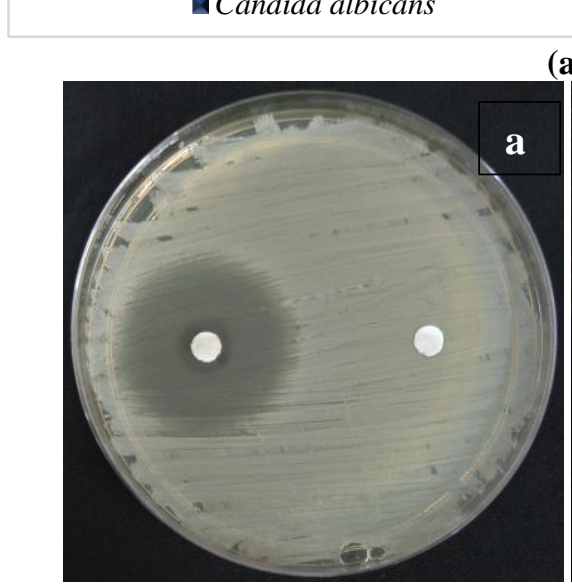

(a)

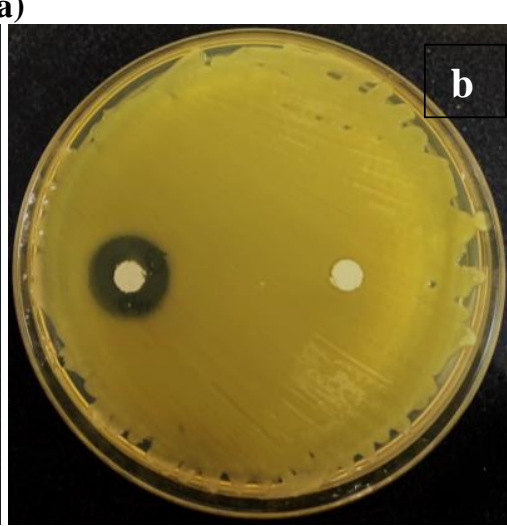

(b)

Fig. 3 (a) Pie graph depicting distribution of isolates exhibiting bioactivity against various pathogens. (b) Bioactivity of B. amyloliquefaciens 5NPA-1 against (a) S. aureus MCC 2043 and (b) X. campestris NCIM 5028 

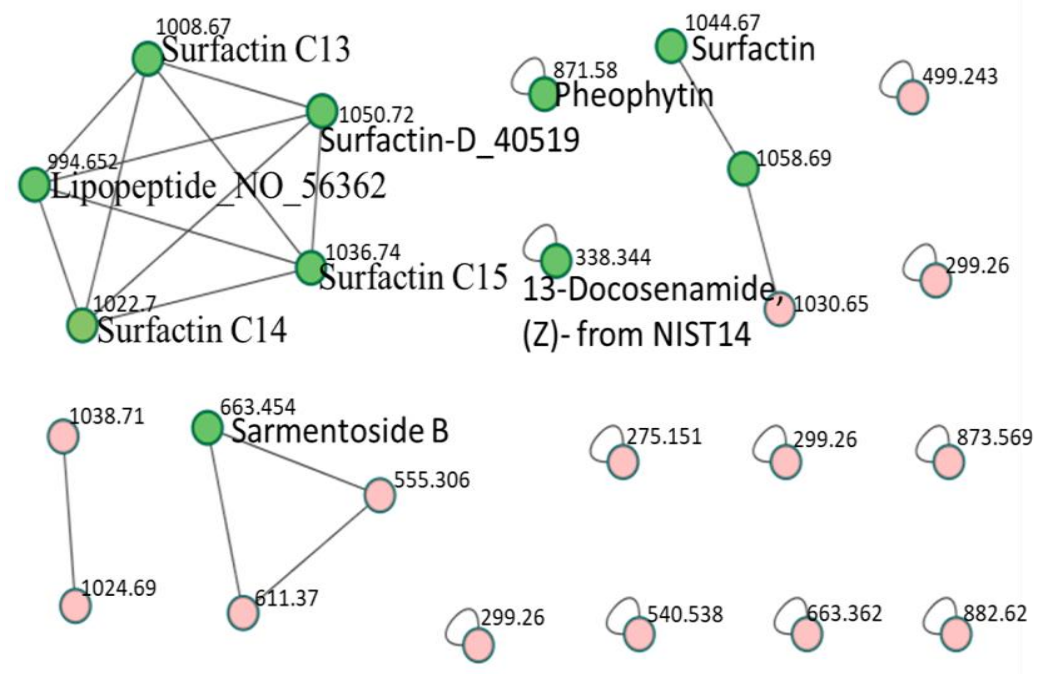

513 Fig. 4 Molecular network of B. amyloliquefaciens 5NPA-1. Annotated molecular network (green) by GNPS for crude extract identifies surfactin networks. Molecular weights beside nodes indicate mass of parent ions. Unidentified nodes (pink) were not automatically detected. 
bioRxiv preprint doi: https://doi.org/10.1101/2020.07.15.203612; this version posted July 15, 2020. The copyright holder for this preprint (which was not certified by peer review) is the author/funder, who has granted bioRxiv a license to display the preprint in perpetuity. It is made available under aCC-BY-NC-ND 4.0 International license.
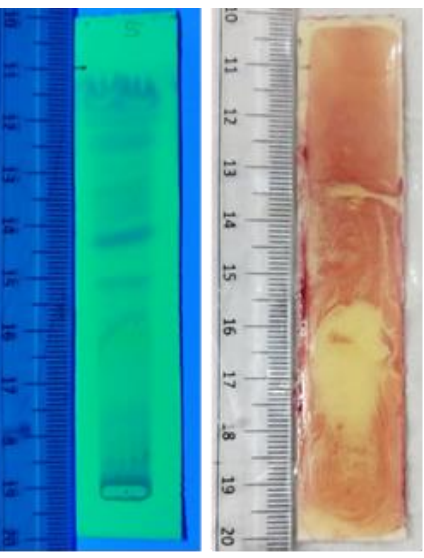

Fig. 5 TLC bioautography plate of crude extract of B. amyloliquefaciens 5NPA-1. Pink area represents cell growth 522 and clear zone area depicts presence of bioactive compound at that region 
bioRxiv preprint doi: https://doi.org/10.1101/2020.07.15.203612; this version posted July 15,2020 . The copyright holder for this preprint (which

was not certified by peer review) is the author/funder, who has granted bioRxiv a license to display the preprint in perpetuity. It is made available under aCC-BY-NC-ND 4.0 International license.

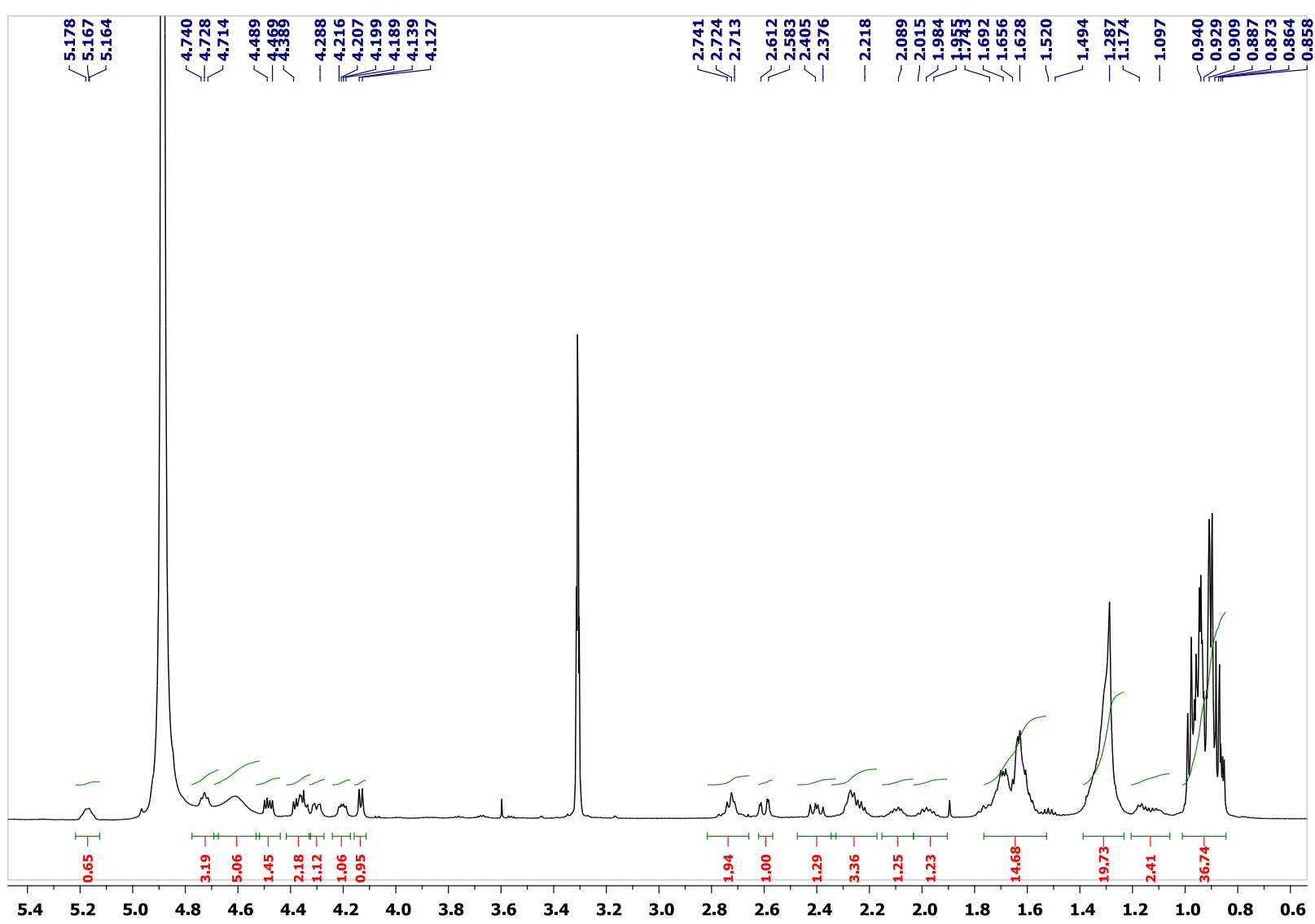

Fig. $6{ }^{1} \mathrm{H}$-NMR spectrum of 5-PTLC2 fraction obtained from preparative TLC of crude extract of $B$. amyloliquefaciens 5NPA-1 


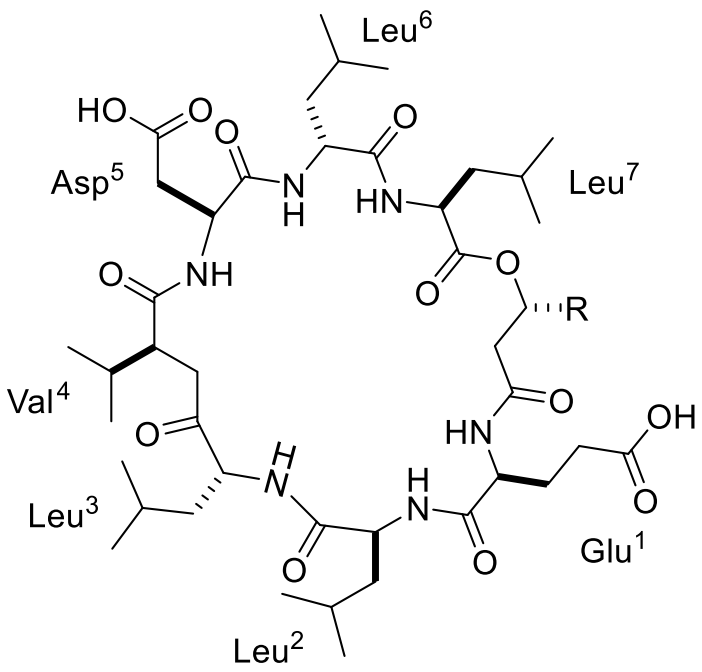<smiles>CCCCCCCCC(C)CC(C)CC</smiles>

(a)
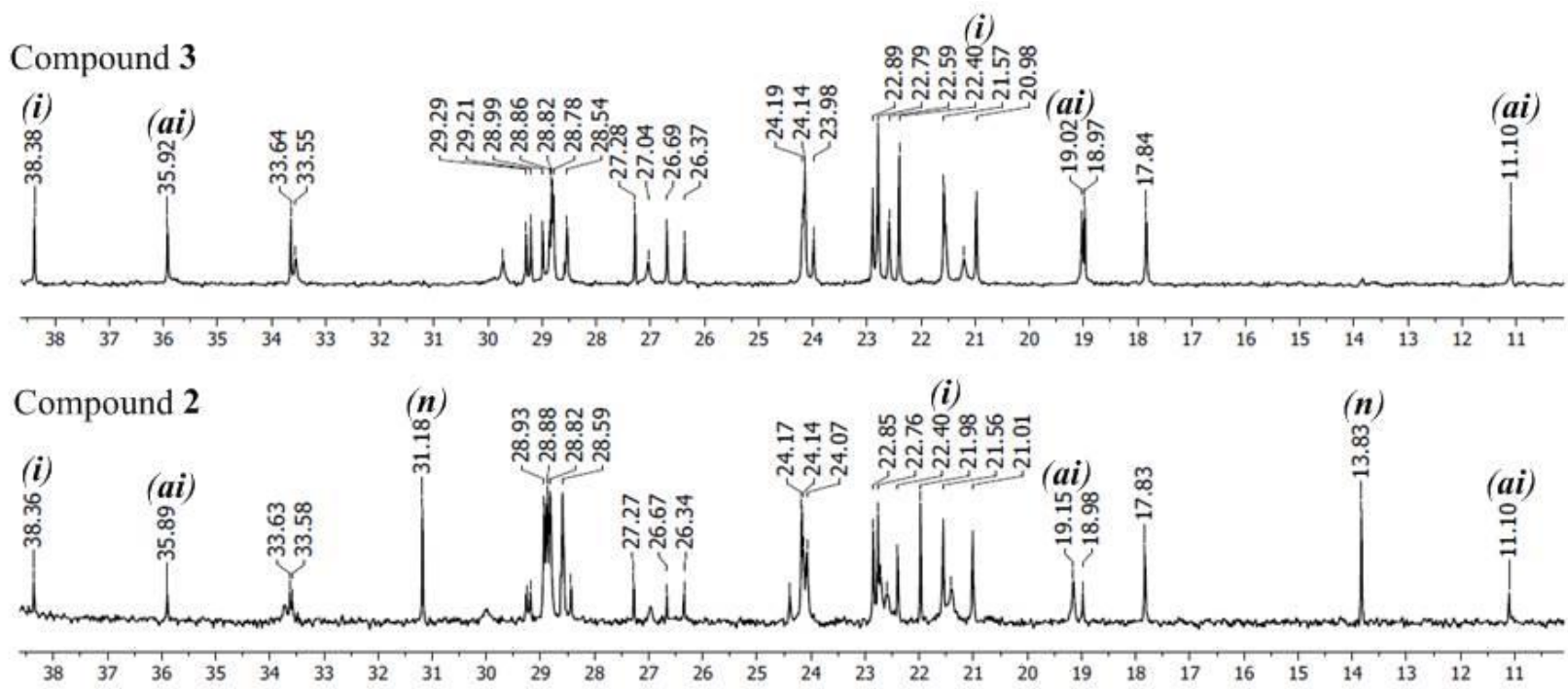

Compound 1

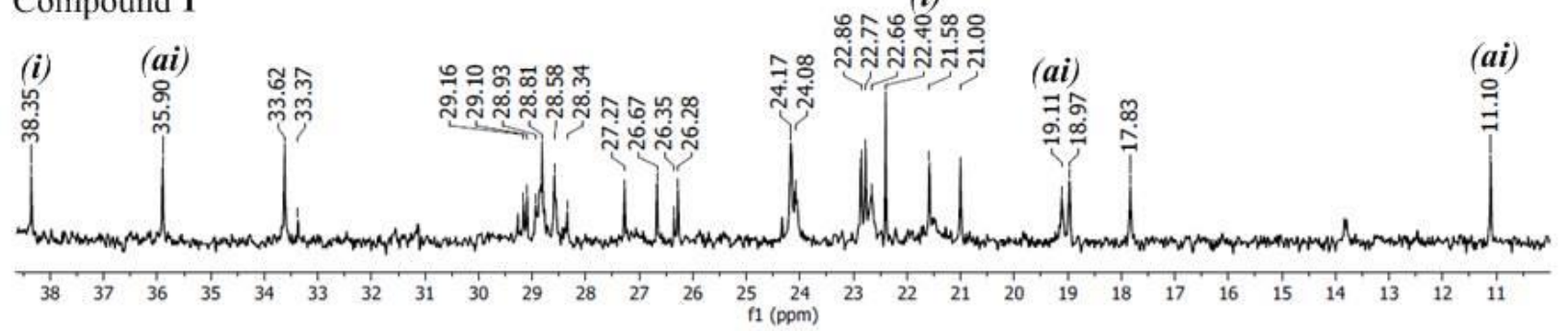

(b)

Fig. 7 (a) Structures of compounds 1 ( $\mathrm{R}=$ mixture of iso- $\mathrm{C}_{10} \mathrm{H}_{21}$ and anteiso- $\mathrm{C}_{10} \mathrm{H}_{21}$ patterns), $2(\mathrm{R}=$ mixture of $n$ $\mathrm{C}_{11} \mathrm{H}_{23}$, iso- $\mathrm{C}_{11} \mathrm{H}_{23}$, and anteiso- $\mathrm{C}_{11} \mathrm{H}_{23}$ patterns), and 3 ( $\mathrm{R}=$ mixture of iso- $\mathrm{C}_{12} \mathrm{H}_{25}$ and anteiso $-\mathrm{C}_{12} \mathrm{H}_{25}$ patterns). (b) Characteristic ${ }^{13} \mathrm{C}$ NMR signals differentiating branching of the hydroxy fatty acid side chains in compounds $1-3$; $(\mathbf{n})$ : normal $\left(\delta_{\mathrm{C}} 13.8,22.0,31.2\right)$, (i): iso $\left(\delta_{\mathrm{C}} 22.4,22.4,27.3,38.4\right)$ and the (ai): anteiso $\left(\delta_{\mathrm{C}} 11.1\right.$, and 19.0$)$ chain type. 